\section{Commentary: Kids are not little adults, but there is no reason they cannot be helped with adult tools}

\section{Joshua L. Hermsen, MD}

Kalangos and colleagues ${ }^{1}$ have provided the congenital surgical community with another case in which outside-thebox thinking and adaptive use of a standard adult prosthesis was used to help a congenital patient. Their patient was post-arterial switch and ventricular septal defect closure who started with an abnormal tricuspid valve and experienced worsening tricuspid regurgitation, right ventricular dilation, and clinical sequelae of portal venous hypertension. The patient had already undergone a valve repair that had failed and had a hypoplastic annulus.

Their solution was to perform valve replacement using a prosthesis designed for aortic valve replacement in adults. Such an adaptation has been reported previously using Melody valves in both tricuspid ${ }^{2}$ and mitral $^{3}$ positions, Sapien valves in the right ventricular outflow tract, ${ }^{4}$ and transcatheter valve-in-valve applications in various congenital pathologies. ${ }^{5}$ Their choice of the Sapien valve over the Melody valve was thoughtful and aimed at a larger patient with an eye toward potential serial dilation to rehabilitate the tricuspid annulus. Indeed, dilation of balloonexpandable prostheses as a child grows is a proven concept. $^{3}$

The authors also borrowed heavily from the adult playbook in the operation using a right thoracotomy approach and performing the operation on a beating heart. Many adult surgeons will perform tricuspid interventions on a beating heart to get real-time feedback on the conduction system and right coronary artery. In this case, the beating heart was chosen to also monitor the potential impact of valve

\footnotetext{
From the Division of Cardiothoracic Surgery, University of Wisconsin-Madison, American Family Children's Hospital, Madison, Wisc.

Disclosures: The author reported no conflicts of interest.

The Journal policy requires editors and reviewers to disclose conflicts of interest and to decline handling or reviewing manuscripts for which they may have a conflict of interest. The editors and reviewers of this article have no conflicts of interest.

Received for publication Dec 15, 2020; revisions received Dec 15, 2020; accepted for publication Dec 21, 2020; available ahead of print Dec 25, 2020.

Address for reprints: Joshua L. Hermsen, MD, Division of Cardiothoracic Surgery,

Department of Surgery, University of Wisconsin-Madison, Madison, WI 53792

(E-mail: hermsen@surgery.wisc.edu).

JTCVS Techniques 2021;6:125

2666-2507

Copyright (C) 2021 The Authors. Published by Elsevier Inc. on behalf of The American Association for Thoracic Surgery. This is an open access article under the CC BY-NCND license (http://creativecommons.org/licenses/by-nc-nd/4.0/).

https://doi.org/10.1016/j.xjtc.2020.12.022
}
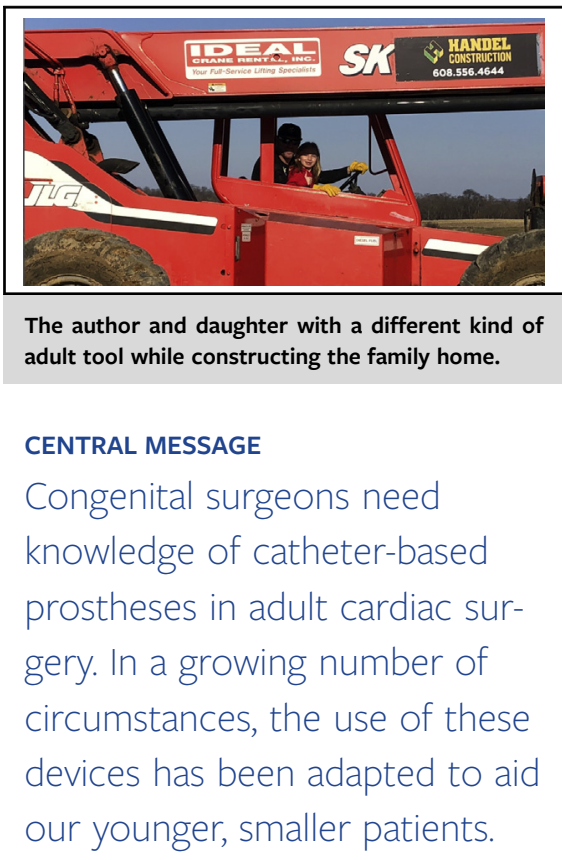

expansion on the left ventricular outflow tract-a smart choice!

The lessons from this experience are to stay "tuned in" to what is happening in the world of heart surgery at large and not be afraid to try to fit a round peg into something slightly less than a round hole. Congenital surgeons are masters of improvisation and dealing with situations not previously encountered. This case is an excellent reminder that there is no reason why our toolbox should not include all the adult tools.

\section{References}

1. Kalangos A, Shatelen N, Sfyridis P, Dalarizou E, Bonou P. Pediatric tricuspid valve replacement with a transcatheter aortic valve (SAPIEN 3). J Thorac Cardiovasc Surg Tech. 2021;6:121-4.

2. Hermsen JL, Permut LC, McQuinn TC, Jones TK, Chen JM, McMullen JM Tricuspid valve replacement with a Melody stented bovine jugular vein conduit. Ann Thorac Surg. 2014;98:1826-7.

3. Pluchinotta FR, Piekarski BL, Milani V, Kretschmar O, Burch PT, Hakami L, et al. Surgical atrioventricular valve replacement with Melody valve in infants and children. Circ Cardiovasc Interv. 2018;11:e007145.

4. Kenny D, Rhodes JF, Fleming GA, Kar S, Zahn EM, Vincent J, et al. 3-year outcomes of the Edwards Sapien transcatheter heart valve for conduit failure in the pulmonary position from the COMPASSION multicenter clinical trial. JACC Cardiovasc Interv. 2018;11:1920-9.

5. Hoendermis ES, Douglas YL, van den Heuvel AF. Percutaneous Edwards Sapien valve implantation in the tricuspid position: case report and review of literature. EuroIntervention. 2012;8:628-33. 